131 ERECTOR SPINAE BLOCK FOR PERIOPERATIVE PAIN MANAGEMENT IN CHILDREN UNDERGOING THORACOTOMY

${ }^{1}$ E Mossad*, ${ }^{2,2}$ E Chung. ${ }^{1}$ Texas Children's Hospital, Houston, USA; ${ }^{2}$ Cook Children's Hospital, Fort Worth, USA

\subsection{6/rapm-2021-ESRA.131}

Background and Aims Thoracotomy for pediatric cardiac surgery can be associated with significant pain. Regional anesthesia techniques such as epidurals and paravertebral blocks can reduce the pain of thoracotomy but can also be associated with significant risk.

The erector spinae plane (ESP) block targets the dorsal and ventral rami of spinal nerve roots and has been used extensively for a host of adult surgical procedures. The ESP block is a less invasive option due to the avoidance of the neuraxial and paravertebral spaces.

Methods We present a case series in which the ESP block was used successfully in 25 pediatric patients undergoing thoracotomy for cardiac surgery. We compare the ESP to other modalities of perioperative pain management in 29 pediatric patients.

Results Patients presented for coarctation repair (5) and vascular ring division (20 patients). The patients ranged in age from 8 months to 17 years of age. The ESP blocks were performed after induction of general anesthesia under ultrasound guidance Intraoperative opioid use was decreased compared to the usual doses used with other blocks or pain management modalities, and post-operative opioid use in the first 24 hours after surgery ranged from 0.05 to 0.5 milligrams per kilogram, significantly lower than other modalities. Postoperative FLACC pain scores were significantly lower in the ESP group in the first 48 hours.

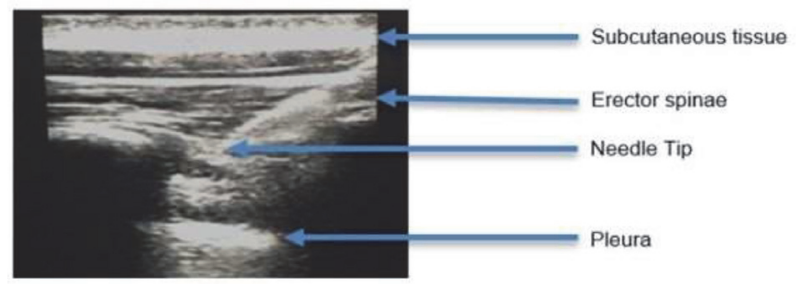

Abstract 131 Figure 1

Conclusions The erector spinae plane block can potentially lead to decreased intraoperative and post-operative opioid use for pediatric patients undergoing thoracotomy for cardiac surgery.

\section{SINGLE SHOT ERECTOR SPINAE PLANE BLOCK IN NEWBORNS UNDERGOING OPEN TYPE C ESOPHAGEAL ATRESIA REPAIR}

O Rahil*. Clinique Universitaire de Chirurgie Pediatrique Ali Bouzid, Algiers, Algeria

\subsection{6/rapm-2021-ESRA. 132}

Background and Aims Erector spinae plane block (ESPB) is a new paraspinal block that provides périopérative pain relief in thoracoabdominal surgery.ESPB seems to be a safe and effective alternative to thoracic paravertebral block. We report our experience in single shot ESPB for post operative pain management in newborns (NB) undergoing open type c esophageal atresia repair.

Methods Sixteen NB scheduled for open type C esophageal atresia repair were included in this prospective observational study (2017-2019). Blocks were performed in intubated asleep patients (propofol \&,or sevoflurane). NB were placed in left Lateral decubitus. A right parasagital ESPB, was performed at the level of the forth dorsal vertebrae (D 04), followed by in plane injection of $0.5 \mathrm{ml} / \mathrm{kg}$ of $0.1 \%$ Bupivacaine. We considered as insufficient surgical analgesia any increase in heart rate beyond 20\% of baseline and requiered rescue intravenous (IV) Alfentanyl $(10 \mu \mathrm{g} / \mathrm{kg})$.Postoperative pain was evaluated using the EDIN scale (every 4 hours) during The first post operative day. All newborns received intravenous paracetamol $(7,5 \mathrm{mg} /$ $\mathrm{kg} / 6 \mathrm{~h})$. We have also noted incidents and complications.

Results 16 patients had a primary surgical repair (14 term $\mathrm{NB}$, and 02 prematures). Mean age was 38 post menstrual weeks (36-41). Mean weight was $2150 \mathrm{~g}$ (1600-3200). Two NB (12,5\%) required intra operative analgesia, but none in postoperative. No pneumothorax nor vascular puncture were noted.

Conclusions Integrated in a multimodal non opioid périopérative pain relief strategy, single shot ESPB seems to be a safe $\&$ effective alternative to tradittional thoracic epidural \& paravertebral blocks, in newborns undergoing open type c esophageal atresia repair.

\section{TRUNCAL (TAP AND QL) BLOCKS FOR APPENDECTOMY IN CHILDREN: A RETROSPECTIVE STUDY OF EFFICACY COMPARED TO GENERAL ANESTHESIA ALONE}

${ }^{1}$ I Kyselova*, ${ }^{2} Y$ Pavlova, ${ }^{1} \mathrm{~V}$ Orel. 'Shupyk National Healthcare University of Ukraine, Kyiv Ukraine; ${ }^{2}$ Kyiv Children's Hospital \#1, Kyiv, Ukraine

\subsection{6/rapm-2021-ESRA.133}

Background and Aims The aim of this study is to evaluate the efficacy of US-guided truncal blocks (TAP and QL) in children undergoing appendectomy.

Methods After approval by the ethics committee we conducted a retrospective study including 204 paediatric patients underwent for appendectomy from April 2020 to April 2021. A group ' $G A$ ' received general anaesthesia alone $(n=142)$, a group 'GA+RA' received GA with ultrasound-guided TAP or QL blocks $(n=62)$. We compared total surgical and anaesthesia time, the needs in opioids intraoperatively, non-opioid analgesia and fluid therapy first 5 days postoperatively, incidences of PONV, duration of the body temperature reaction, length of hospital stay (LOS), using Mann-Whithney U-test, chi-square and Fisher's exact tests.

Results Patients in both groups were comparable in age, body weight, ASA status. Total surgical time including anaesthesia was longer in 'GA+RA' group $[1,63(0,6)$ vs $1,34(0,6)$ hours, $\mathrm{p}<0,001]$. Patients in 'GA+RA' needed significantly less doses of phentanyl intraoperatively $[4,5(2,4)$ vs $7,0(3,6) \mathrm{mkg} / \mathrm{kg} / \mathrm{h}$, $\mathrm{p}<0,001]$, despite of that, there was no difference in incidences of PONV between groups. 34\% of patients in 'GA+RA' and $58 \%$ of patients in 'GA' needed additional analgesia in the end of surgery $(p=0,003)$, but needs in non-opioid analgesia in 1-5 days after surgery were comparable. We didn't observe differences in duration of temperature reaction, fluid therapy, as well as in LOS after surgery. 
Conclusions Results of our study suggest that combined general anaesthesia with truncal blocks such as TAP or QL for appendectomy in children may lengthen operative time, reduce the needs in analgesics, but do not effect on general outcomes.

\section{THE IMPACT OF INTRAVENOUS LIDOCAINE IN CHILDREN AND YOUNG PEOPLE UNDERGOING SPINAL FUSION SURGERY: THE EXPERIENCE IN A UK SPECIALIST CHILDREN'S HOSPITAL}

JE Bordoni*, S Siew, J Keough, M McMonagle, R Ravi, R Diwan, I Okonkwo. Alder Hey Children's Hospital NHS Foundation Trust, Liverpool, UK

\subsection{6/rapm-2021-ESRA.134}

Background and Aims The use of intravenous lidocaine therapy (IVLT) improves pain outcomes in certain adult populations, however, little evidence exists in paediatric populations. We aim to evaluate its impact in patients with adolescents idiopathic scoliosis(AIS) undergoing primary posterior spinal instrumentation and fusion (PSIF).

Methods ASA1 and ASA2 patients over 12-years-old undergoing PSIF surgery for AIS between January 2017 and December 2020 were reviewed retrospectively. Demographic data, anaesthetic and pain management were evaluated alongside postoperative outcome measures.

This service evaluation was deemed no to require ethical approval (http://www.hra-decisiontools.org.uk/research/docs/DefiningResearchTable_Oct2017-1.pdf) by our local clinical governance committee (Audit No. 6351)

Abstract 134 Table 1 Outcomes and characteristics of 45 patients undergoing PSIF

\begin{tabular}{|c|c|c|c|c|}
\hline & & 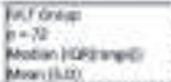 & 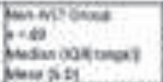 & Focka \\
\hline \multirow{9}{*}{ g } & havid & gaxessmen & monisestrit & 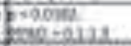 \\
\hline & 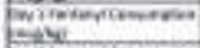 & 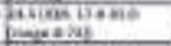 & 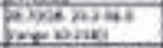 & $\sin =12$ \\
\hline & 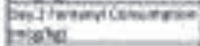 & 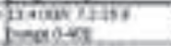 & 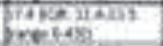 & fowow \\
\hline & Holathesy & 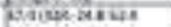 & 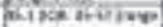 & Habes \\
\hline & 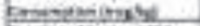 & Deasitul & brome & 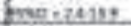 \\
\hline & 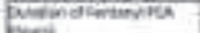 & 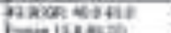 & 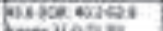 & Foces \\
\hline & Yers: & Es:14:52 & 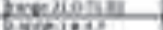 & 280.1111 \\
\hline & 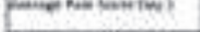 & monstionos & fancies. & 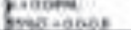 \\
\hline & penevialinewtans & 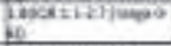 & 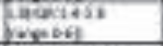 & Guation \\
\hline \multirow{4}{*}{$\frac{5}{5} \frac{2}{2}$} & Foiven & 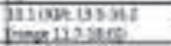 & 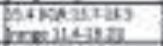 & Folist \\
\hline & Fis & swonis & pionis in & $\begin{array}{l}\text { grave } \\
\text { posis. }\end{array}$ \\
\hline & $\lim _{i \rightarrow 2}$ & $\begin{array}{l}\text { whinen } \\
\text { gonirs }\end{array}$ & Eviviow & benting \\
\hline & Boneriverviant & 13ak & tion 10 & Konghe \\
\hline \multirow{4}{*}{$\frac{3}{5}$} & 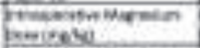 & papor wos & 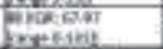 & 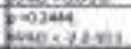 \\
\hline & 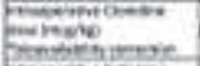 & Howerids & 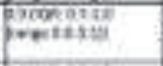 & 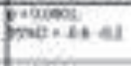 \\
\hline & 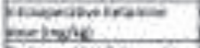 & Wocerast & 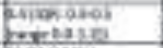 & Fonsed \\
\hline & 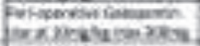 & monowe & Binentione & Foosen \\
\hline \multirow{3}{*}{$\frac{71}{31}$} & rownesty & कmprov & mave & granowist \\
\hline & winhe & Pantaning & 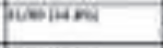 & 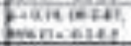 \\
\hline & GWINON & Drsthe & 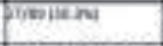 & 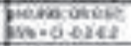 \\
\hline \multirow{3}{*}{$\frac{5}{2}$} & 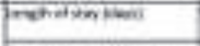 & 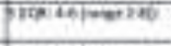 & कan & Faned \\
\hline & fasor Woustians & mocinivento & 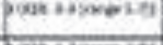 & Eacha \\
\hline & 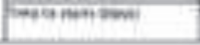 & 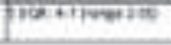 & 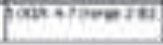 & Gration \\
\hline
\end{tabular}

Results 162 patients with a median age of 15.2(IQR:13.6-16.5 [range 11.4-19.2])years underwent PSIF for AIS. 33/162 $(20.4 \%)$ were male and $129 / 162(79.6 \%)$ female. $73 / 162$ (45.1\%) received IVLT at a median infusion-rate of $1.8(\mathrm{IQR}$ : 1.5-1.9 [range 1.1-2.0]) $\mathrm{mg} / \mathrm{kg} / \mathrm{hr}$. These patients required significantly less fentanyl: intraoperatively $(p=0.0182,95 \%$ $\mathrm{CI}=0.1-1.3)$, on day-1 $(\mathrm{p}=0.0032 ; 95 \% \mathrm{CI}=1.6-7.6)$ and day-2 $(\mathrm{p}=0.0104 ; 95 \% \mathrm{CI}=0.8-6.5 \quad$ (see table 1$)$; reported similar/ lower pain scores (day 1: $\mathrm{p}=0.0494 ; 95 \%$ CI $0.0-0.8$ ) and attained rehabilitation goals in similar timeframes.

Conclusions We observed the use of intraoperative IVLT to be associated with a significant reduction in early opiate requirements in paediatric PSIF, suggesting patients may benefit from earlier conversion from intravenous to oral opiates. This change has been implemented within our local Enhanced Recovery After Surgery Programme to facilitate earlier mobilization and discharge. Our patients reported similar levels of comfort and attained their rehabilitation goals in a similar timeframe. Further review and study is required to determine the optimal components and dosing within paediatric PSF ERAS programmes.

\section{Peripheral nerve blocks}

\section{IPACK AND ADDUCTOR CANAL BLOCK VS PERIARTICULAR INJECTION; ENHANCES POSTOPERATIVE PAIN CONTROL IN ANTERIOR CRUCIATE LIGAMENT (ACL) REPAIR: A RANDOMIZED CONTROLLED TRIAL}

A AlJa'bari*. DMF Hospital, Riyadh, Saudi Arabia

\subsection{6/rapm-2021-ESRA. 135}

Background and Aims Motor-sparing peripheral nerve blocks, such as the infiltration between the popliteal artery and capsule of the knee (IPACK) and the adductor canal block (ACB), may augment PAI in multimodal analgesic pathways for knee surgery, but supporting literature remains rare. We hypothesized that ACB and IPACK would lower pain on ambulation on postoperative day (POD) 1 compared to PAI alone.

Methods This triple-blinded randomized controlled trial included 50 patients undergoing ACL repair. Patients either received (1) a PAI (control group, $\mathrm{n}=26$ ) or (2) an iPACK with an ACB (intervention group, $\mathrm{n}=24$ ). The primary outcome was pain on ambulation on POD 1. Secondary outcomes included numeric rating scale (NRS) pain scores, patient satisfaction, and opioid consumption.

Results The intervention group reported significantly lower NRS pain scores on ambulation than the control group on POD 1( 3.3 [2.7 to 4.0]; P <0.001). In addition, NRS pain scores on ambulation on POD 0 (3.5 [2.7 to 4.3]; $\mathrm{P}$ $<0.001)$ and POD 2 (1.0 [1.0 to 1.9 ]; $\mathrm{P}=0.033)$ were significantly lower. Patients in the intervention group were more satisfied, had less opioid consumption $(\mathrm{P}=0.005$, PACU, $\mathrm{P}=0.028$, POD 0$)$, less intravenous opioids $(\mathrm{P}$ $<0.001)$, and reduced need for intravenous patient-controlled analgesia $(\mathrm{P}=0.037)$.

Conclusions The combination of iPACK to ACB significantly improves analgesia and reduces opioid consumption after ACL repair compared to PAI alone. This study strongly supports iPACK and ACB use within a multimodal analgesic pathway. 